\title{
Risk measurement and control of financial derivatives hedging
}

\author{
Shan Guan ${ }^{1, a}$ and Jiaming Zhu ${ }^{2, b}$ \\ ${ }^{1}$ School of Finance, Anhui University of Finance and Economics, Bengbu, 233030, China; \\ ${ }^{2}$ School of Statistics and Applied Mathematics, Anhui University of Finance and Economics, Bengbu, \\ 233030, China \\ a18895675874@163.com, brhujm1973@163.com
}

Keywords: Financial Derivative Products; Hedging; Risk Measurement; Control Mode.

\begin{abstract}
Hedging is one of the most important causes of all financial derivatives, and an important tool for enterprises to avoid risks. For the risk measurement and control of financial derivatives hedging, this paper introduces the principle and development of hedging in financial market, explores the potential risks of enterprises in hedging, and puts forward some policy suggestions on how to deal with and control the risk of hedging.
\end{abstract}

\section{Introduction}

With the opening and development of financial market, the hedging portfolio is widely used by traders to maximize utility and minimize risk, which becomes an important way of risk prevention and management. In the interest rate, exchange rate, securities and other forms of transactions, hedging mainly avoids risks through four forms of forward, swaps, options and futures. However, hedging has high leverage and high risk. Once the enterprise personnel employ improper operation strategies, it is more likely to cause huge losses to the company. For the risk measurement and control of financial derivatives hedging, this paper expounds the basic principles and potential risks of hedging, and provides reasonable policy recommendations for enterprises on how to deal with and control the risk of hedging better.

There are four parts in this paper. The first part is an introduction, which points out that hedging is a double-edged sword" .It can not only bring huge profits to the enterprises through the risk management, but also can damage the enterprises because of its potential risks. The second part is the basic principles of hedging. The third part discusses the existence of hedging risk, and the fourth part is about how to deal with and control the risk of hedging.

\section{Basic principles of hedging}

Futures contracts are the most commonly used financial derivatives instruments in traditional hedging. The two sides in transaction are worried about the fluctuations of a certain asset prices in future, therefore, through the signing of futures contracts providing that both sides could clear and deliver a certain amount of standardized assets at a certain time in the future, they can lock the price of the underlying asset in advance.

There are two markets independent but affected by common factors, called forward market and cash market in the financial marketplace. Although the two separate from each other, they are affected by the same economic factors, and this is the reason why the cash market price movements and volatility must be consistent with the forward market. It is the law of price convergence in the futures market and spot market that provides a space for hedging. A business operator who buys or sells a spot in the spot market, shall sell or buy a futures contract (commodity, interest rate, foreign exchange, etc.) in the forward market, which has the same variety, equal quantity but the opposite direction as the spot to offset or compensate for losses in another market with a market profit. Thus can establish a hedging mechanism between the spot and futures contracts, and avoid the risk of price fluctuations[1]. 
Hedging follows four operating principles, which are the opposite direction, the same or similar commodity, the equal or similar goods quantity and the same or similar month. For example, a farmer who provides agricultural products to the market worries that he will not be able to sell products at a better price after the autumn harvest in October because of falling prices of spots, then he considers locking the price to keep production profit through hedging. Assuming May's spot price is 100 yuan / ton, quite considerable for him, so he will choose hedge selling in May, and short a 100 yuan / ton November futures contract. By November, spot price has become 70 yuan / ton. The farmer can only sell products by 70 yuan / ton, less 30 yuan than May; but the futures contract was 30 yuan more than in May. It is explained that this farmer still sells his agricultural products at the equivalent of final price of 100 yuan per ton and maintain his own operating profit finally.

\section{Potential risks of hedging operations}

One of the founders of China's futures market, Chang Qing has expressed such thoughts: Enterprises with demand are certain to reduce the risk through hedging. However, Hedging is by no means random speculation. That warns enterprise managers hedging in the futures market to pay attention to the timing and strategy of hedging [2]. In the second half of 2008, for the sake of hedging against rising prices, three domestic airlines bought a large number of call options, while selling put options. Unfortunately, 2008 global financial crisis swept over the world. As a result, the price of crude oil was affected by the crash and fell sharply, which caused a huge capital loss to these three airlines. Put options sold for hedging turned into an enormous loophole, and the loss had been close to 8 billion by the end of the year. From the case that China's airlines suffered heavy losses due to improper hedging strategy in 2008, we can know that enterprises must consider the economic background and political environment at home and abroad and make clear the purpose and direction of hedging in the choice of hedging financial derivatives.

The risks faced by enterprises in hedging are classified into two categories: One is the endogenous risk, that is, the potential risk of hedging. Another is exogenous risk, from the wrong operation of hedging and the wrong use of financial derivatives [1].

\subsection{Endogenous risk.}

Basis risk, credit risk is mainly endogenous risk hedging. Even if the hedging process is completely correct, the endogenous risk remains.

Basis risk is the main endogenous risk. The basis is the difference between the assets of spot price and futures price index, expressed as a formula:

Basis $=$ spot price - futures price.

The basis consists of two parts namely the transportation cost and holding cost. The transportation cost determines that the basis risk changes due to the different locations. The holding cost includes storage, consumption, insurance and so on, which reflects the difference between the futures market and spot market price in different time, such as the interval of delivery month. The sources leading to the basis are diverse. The price differences between the underlying assets and the risk assets for hedging, time for hedging, matching degree of futures and spot, as well as fluctuations in the holding cost all affect the size and trends of basic level.

If the basis is in the favorable direction, the enterprise may obtain excess profit. Otherwise, when the basis changes in the negative direction, the effect of hedging enterprises will be weakened, and therefore they would suffer losses.

Risks that the counterparty suffers a loss because of fluctuations in the price of underlying financial products on prompt day, or the counterparty is unwilling or unable to perform the contract on the expiry date are given a general designation: credit risk. Credit risk is very common in the hedging of financial products, and the margin system in futures trading system is also set up to avoid credit risk.

\subsection{Exogenous risk.}

Exogenous risk is the risk caused by the improper operation of the derivative financial instruments, mainly composed of operational risk and moral hazard. 
The root cause of operational risk is the lack of supervision on hedging behavior. What's more, the government hasn't built up the complete and sound risk prevention laws, giving the possibilities for futures trading personnel in some companies to make illegal operations, break the rules of market transactions and disobey the relevant provisions of the transaction such as position limits, stop points, etc. Due to the low transparency of the operation management system, once the operators abuse their power or misappropriate occupied funds, it will directly cause the accumulation of potential risks, resulting in huge losses of the company.

Under the circumstance of asymmetric information, it will lead to moral hazard when one side of the hedge intends to harm the interests of the counterparty activities. For instance, when banks recommend financial products to enterprises, they will deliberately conceal the potential risks of the product, exaggerating the functions and returns of such financial products. As long as the price fluctuates in the financial market, the purchaser of the product is likely to suffer huge losses ${ }^{[1]}$.

\section{Policy recommendations for controlling hedging risk}

Through the development of the financial derivatives market, we have found that the leverage function of financial derivatives may bring huge profits to hedgers, but it also pays new risks while defusing financial risks. For the government, it should learn from the mature risk management experience of the West and take the necessary measures to minimize the risk of the derivatives market. As for enterprises, the essentials to take hedging better are that following principles of hedging transactions and mastering the relevant strategies to control risk.

\subsection{Measures for Government to avoid hedging.}

(1)Enhance the ability to diversify the risk of hedging, and establish effective risk assessment and management mechanism. The government should use the risk assessment methods, such as the stress test method and the risk value method to accurately measure the maximum risk limit that transaction subjects can tolerate, and improve the relevant laws and regulations to establish the efficient and fair derivatives market, which can reduce the potential risk of enterprises.

(2)Improve China's accounting system and tax system, and establish adequate links with the international derivatives market. Fluctuations in exchange rates, interest rates ${ }^{[3]}$ and other factors on financial markets will increase the risk and uncertainty of hedging and weaken the investors' confidence in the market. Therefore, the government should promote the domestic derivatives market with international standards, improve the relevant standard system, and effectively ensure the safety and reliability of hedging.

\subsection{Principles and strategies of corporate risk control.}

(1)Enterprises should use the correct hedging tools and design the reasonable risk-averse strategy. Faced with the uncertainty of price, large-scale enterprises should spare no effort to design hedging strategies reasonably for locking the price and hedging risks. Correct hedging tools and reasonable stop-loss strategies are keys to avoiding an unknown risk.

(2)Enterprises should focus on cultivation and construction of high-quality professional talents. Corporate hedging operators must be proficient in financial market-related knowledge and have a wealth of work experience and sensitive market responsiveness. If necessary, hire cutting-edge technical staff in the financial sector for training enterprise staff skills and planning the direction and strategy of company's hedging.

(3)Enterprises must strengthen the supervision and punishment of internal irregularities, and promote the construction and development of derivative trade system regulations. Managers ought to standardize the transaction behaviors of enterprise hedging operators, ensuring the transparency of the transaction information. For the loss caused by improper operation, it is necessary to increase the intensity of individual accountability, following the principle about integration of power and responsibility ${ }^{[4]}$ and punish them depending on the seriousness of the circumstances.

(4)Clarify the overall development direction of enterprise hedging and strengthen the macro-control of derivatives trading activities. Enterprises should regard hedging strategies as part of the daily 
production and operation and improve the ability to use derivatives to hedge. As China's derivatives market hasn't been mature yet, it's best to give priority to domestic market rather than overseas hedging activities, to avoid the risk of financial derivatives market as far as possible.

\section{Conclusion}

It requires the joint efforts of government and enterprises to hedge successfully by derivative financial instruments. Only when enterprises comply with the operating rules of hedging and invest in hedging scientifically and flexibly, the risk of hedging will be reduced reasonably ${ }^{[5]}$ and their profits will reach the maximum.

\section{References}

[1]. KONG Hong, YUAN Ying, WANG Qingfang. "Hedging and risk management of financial derivatives" [J].Financial theory and Practice, 2010, (05).

[2]. DAI Zhiguang, "Research on hedging motives and effects" [D]. Dongbei University of Finance and Economics, 2014.

[3]. WANG Yisong, "Research on the application of financial derivatives in exchange rate risk management", [D]. East China Jiaotong University, 2013.

[4]. Su Ke, "Research on the supervision of Chinese enterprise hedging" [D]. Capital University of Economics and Business, 2014.

[5]. Hu Yunjie, "The strategy analysis of the hedging of derivative financial instruments" [J]. China Business \& Trade, 2012, (35):123-124. 